\title{
Description of male, pupa and larva of Neolasioptera cerei Rübsaamen (Diptera, Cecidomyiidae)
}

\section{Valéria Cid Maia $^{1}$}

\begin{abstract}
Neolasioptera cerei Rübsaamen, 1905 (Diptera, Cecidomyiidae) associated to Selenicereus setaceus (SD) Berg (Cactacae) is redescribed. Until now, only female was known. Male, pupa and larva are described and illustrated herein.

KEY WORDS. Diptera, Cecidomyiidae, Neolasioptera cerei, taxonomy
\end{abstract}

Neolasioptera cerei Rübsaamen, 1905 is a gall midge that induces galls on Selenicereus setaceus (SD) Berg (Cactaceae) and until now it was known only from its female and gall. There are only two references to this gall maker: RÜBSAAMEN (1905) and GAGNÉ (1994).

Galls of Neolasioptera cerei were collected in Reserva Biológica de Rio das Pedras (Mangaratiba, Rio de Janeiro, Brazil), in June, 1997. They were carried to Diptera laboratory in plastic bags, where galls were maintained in small pots covered with transparent voile, in order to obtain adults. They emerged approximately a month later.

The material was prepared following the methods described in GAGNÉ (1994), except for the immersion in acetic carmine for five minutes after emerging it in acetic acid. This procedure makes observation of the specimens easier. After the acetic carmine, the material returned to acetic acid for another five minutes.

Neolasioptera Felt, 1908 is considered as a catchall group. It includes about 70 species in neotropical region, and until now only one $-N$. cere $i$ - has been associated with Cactaceae. It has only been recorded in Cabo Frio (State of Rio de Janeiro, Brazil). The male, pupa and larva of $N$. cerei are very peculiar. The first one is remarkable for its $7^{\text {th }}$ and $8^{\text {th }}$ tergites (projected to ventral side), the second for its additional antennal tooth and the latter for its spatula medial tooth (longer than the lateral teeth).

\section{Neolasioptera cerei Rübsaamen, 1905}

Figs 1-6

Male. Body length: 2.0-3.0 mm (N=9); wing length: 1.3-1.8 mm $(\mathrm{N}=10)$. Head: eyes with circular facets. Antenna: 15 flagellomeres, the first and the second one are fused, 1-12 quadrate, 13-15 ovoid, circunfila X-shaped. Mouthparts: labrum long-attenuate, labellae hemispherical and setose; palpus four-segmented: segment 1 the shortest, segment 2 the widest, 3 and 4 subequal in length, all with setae.

1) Museu Nacional, Universidade Federal do Rio de Janeiro. Quinta da Boa Vista, São Cristóvão, 20940-040 Rio de Janeiro, Rio de Janeiro, Brazil. Fellowship CAPES. 
Thorax: mesonotum with four longitudinal setal rows; anepimeron with longitudinal row of discal setae; anepisternum bare. All legs with tarsal toothed claws and longer than empodium; wing: venation as in female. Tergites 1-6 rectangular, entirely sclerotized, with a caudal row of setae, no lateral setae and covered elsewhere with scales; tergites 7 and 8 descending laterally and reaching the ventral side (Fig.1), the last one is like a linear band and ends near the sternite; sternites 1-8 square, partially sclerotized, with lateral setae, a caudal row of setae and covered elsewhere with scales. Male terminalia (Fig. 2): gonocoxite elongated 2.8 times as long as wide; gonostylus setulose at basal third and striated elsewhere, 3.3 times as long as wide (subasal length), enlarged at basal third; parameres setose, long, wider at basal half and abruptally attenuate at distal half; hypoproct setose, longer than cerci, not divided into lobes and rounded apically; cerci deeply bilobed (lobes rounded apically and setose); aedeagus triangular, attenuate at apex and longer than parameres.

Pupa. Body length: 2.7-3.1 mm (N=5). Head (Fig. 3): upper margin with two lateral thickenings (one per side); antennal horn well developed (length: 0.23-0.27 $\mathrm{mm}, \mathrm{N}=5$ ) and toothed, two additional horns per side (the lateral one with 0.04-0.06 $\mathrm{mm}$, the other with 0.07-0.1 $\mathrm{mm} ; \mathrm{N}=5$ ). Two pairs of vertical papillae (one nonsetose and one setose - apical setae length: 0.15-0.18 mm, $\mathrm{N}=5$ ); facial papillae absent. Prothoracic spiracle not long (length: $0.08-0.1 \mathrm{~mm}, \mathrm{~N}=5$ ). Wing shield reaching the half length of segment IV. Foreleg shield reaching distal margin of abdominal segment VI to basal third of abdominal segment VII. Midleg shield reaching the half of abdominal segment VIII. Hind leg shield overpassing the last abdominal segment. Diminute spinules covering almost entirely abdominal tergites 2-8 (Fig. 4).

Larva. Yellow. Body length: 1.9-2.2 mm $(\mathrm{N}=3)$. Spatula three-toothed (medial tooth longer than the lateral ones) and with $0.8-1.2 \mathrm{~mm}$ of length $(\mathrm{N}=3)$ (Fig. 5). Four lateral papillae per side: 2 non setose and two setose. Eight terminal papillae (two shorter than the others). Material examined (on slide). BRAzIL, Rio de Janeiro: Mangaratiba (Reserva Biológica de Rio das Pedras), 20.VI.1997, C. Lamas leg.: 7 male, 5 female, 7 exuviae; 01.VIII.1998, V.C. Maia leg.: 06 larvae.

Additional material (in 70\% alcohol): BRAZIL, Rio de Janeiro: Mangaratiba (Reserva Biológica de Rio das Pedras), 20.VI.1997, C. Lamas leg.: 6 male, 25 female, 30 exuviae.

All specimens (including gall) are deposited in the Diptera collection of Museu Nacional (MNRJ).

Gall (Fig. 6). Length: 1,7 cm.Many-celled swelling on Selenicereus setaceus (SD) Berg (Cactaceae). Mature galls with opercules.

These galls also were observed at Restinga of Barra de Maricá and Restinga of Itaipuaçu (Rio de Janeiro State). 


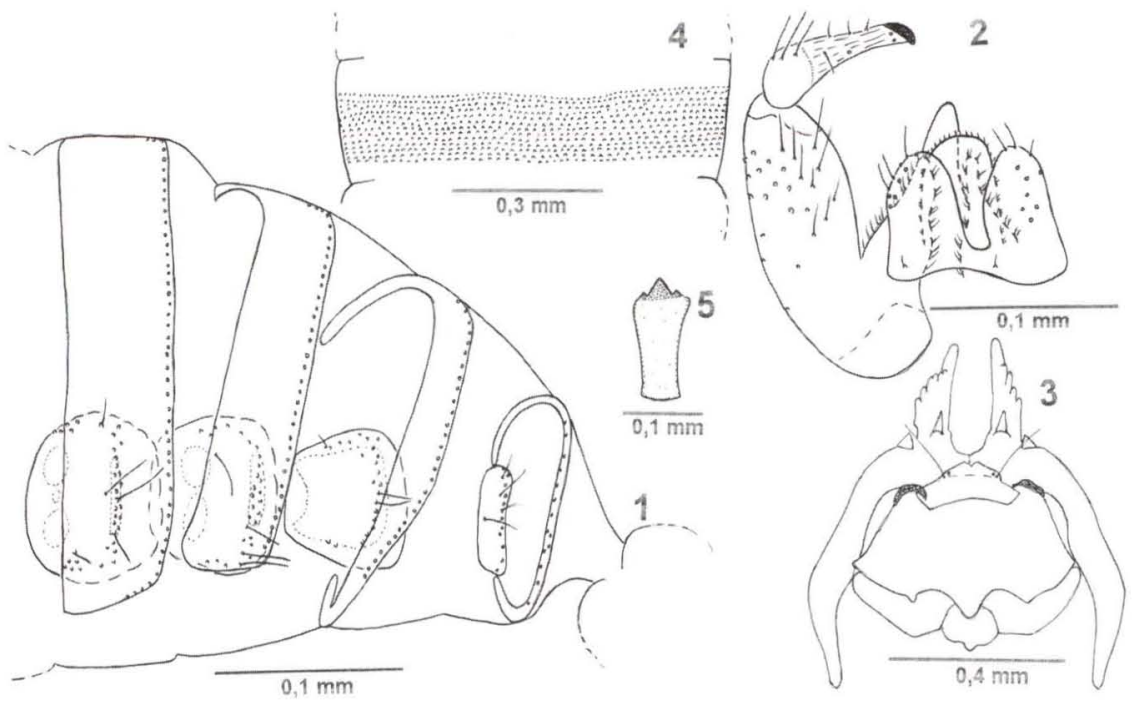

Figs 1-5. Neolasioptera cerei. (1) male, abdominal segments 5-8, dorsal; (2) male terminalia, dorsal; (3) pupa, head, frontal; (4) pupa, abdominal segment 8; (5) larva, spatula.

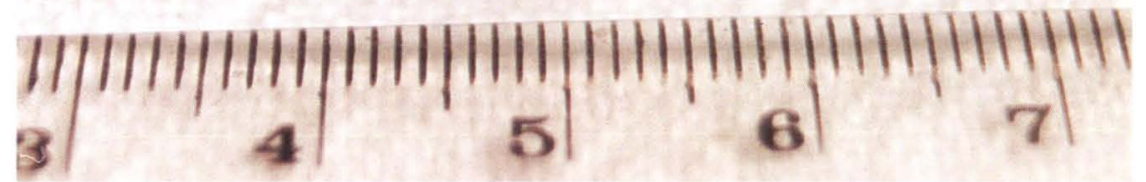

Fig. 6. Gall of Neolasioptera cerei on Selenicereus setaceus, general aspect. 


\section{REFERENCES}

GAGNÉ, R.J. 1994. The gall midges of neotropical region. Ithaca, Comstock Cornell University Press, 352p.

RÜBSAAMEN, E.H. 1905. Beiträge zur Kenntnis aussereuropäischer Zoocecidien.II.

Beitrag: Gallen aus Brasilien und Peru. Marcellia 4: 65-85.

Recebido em 22.I.1999; aceito em 17.XI.1999. 